\title{
Drug Shortages through the Decades: A Big-Picture Perspective
}

James L Mann

$\mathrm{H}$ ospital pharmacy has enjoyed a long relationship with the pharmaceutical industry. In the late 1960s and 1970s, hospital pharmacists championed the development of group purchasing organizations (GPOs), pooling the purchasing power of individual institutions into larger, but still manageable, groups of hospitals. The GPOs developed reliable strategies for establishing the quantities of each pharmaceutical product that the group would purchase. Hospital pharmacy departments monitored inventory turns and minimized holding costs before this approach became the norm in the health care industry. Negotiations with industry were based on positive supplier relationships built not solely on price, but also on numerous other considerations. For example, purchasing decisions could be linked to vendors' willingness to adhere to packaging and labelling standards, such as those developed by the Canadian Society of Hospital Pharmacists (CSHP), ${ }^{1}$ and to each vendor's history of dealing with drug shortages and other limitations. The GPOs evolved and improved through the dedication of the pharmacists who met with their colleagues 2 or 3 times a year to define their needs and preferences. Hospital pharmacy enjoyed industry fill rates of $98 \%$ to $99 \%$, on-time deliveries, and company representatives who were willing and able to accommodate circumstances unique to a particular hospital.

Hospital pharmacy managers justified IV additive programs to hospital administrators, which led to contracts with pharmaceutical companies that could supply products to facilitate the work of hospital pharmacists and ensure a dramatically safer system for patients. We kept industry leaders in business by according innovative players a share in the market, as opposed to allowing established suppliers to keep "newbies" out by lowering their prices. Suppliers knew that the GPOs were negotiating in good faith; they knew that in the absence of unforeseeable circumstances, hospital pharmacies would live up to their purchase commitments.

Today, most hospitals and health regions have joined large corporate GPOs that negotiate contracts "on behalf of" hospital pharmacies, with limited understanding of the complex nature of drug use in the hospital setting. Many industry representatives have been eliminated or assigned responsibility for so many hospitals that the development of relationships with individual clients is impossible. As a result, service has declined. This trend is particularly notable for daily order fill rates, which have dimin-

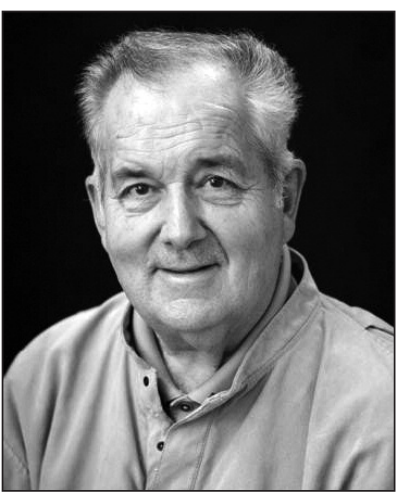

ished substantially, often to the $80 \%$ range. The profession now finds itself having to supply drugs other than first-choice agents, products that are potentially less effective and/or more toxic and usually more expensive than the first-choice agent. Drug shortages also consume immense amounts of pharmacy human resources, negatively affecting direct patient care responsibilities. Recently, Sellinger ${ }^{2}$ summarized results from a survey conducted by the CSHP, the Canadian Pharmacists Association, and the Canadian Medical Association to determine the impact of drug shortages on pharmacists, physicians, and patients. Hospital pharmacist respondents reported spending considerable time dealing with shortages, including communicating with stakeholders, rationing medications, compounding from alternative concentrations or formulations of the same medication, changing the route of administration, or altering therapy to a medication not currently in shortage. ${ }^{2}$ Additional patient safety concerns are arising, such as drug substitutions that require changes to the drug libraries used in "downstream" technologies like smart IV infusion pumps. ${ }^{3}$

Vaillancourt ${ }^{4}$ recognized the need to maintain healthy competition in the Canadian drug market to secure the supply chain for essential drugs and suggested that contracts be split among 2 or 3 suppliers to ensure that more than one manufacturer is able to maintain a production line. We need to ask the GPOs to pursue such multisource contracts for a majority of 
products, as a fundamental part of the drug supply chain. In the same context, "suppliers must be willing to provide a competitive bid even if they do not get $100 \%$ of the business, and hospitals must be willing to pay more for part of the contract." ${ }^{\prime \prime}$

Another issue is how the pharmaceutical industry will be held accountable, either directly to the GPOs or to the hospitals that the GPOs represent. What quality management principles for vendors are embodied in the contracts with GPOs? How are rebates being allocated, and are those arrangements interfering with optimal contracting processes? How are GPO costs and profits being managed? What recognition is accorded to pharmaceutical companies that have emphasized customer service, avoided back-order problems, and maintained quality management principles?

The pharmacy profession needs to quantify the impact of supplier-based drug shortages and back orders. Drug shortages have become a demanding issue that often requires a full-time pharmacy technician (or pharmacist, in smaller facilities) to track down an alternative supply of medication for back-ordered products. Managers in many hospitals are now expending the equivalent of a full-time technician's salary (roughly $\$ 50000$ per year) on an external supply problem. A crude extrapolation to the approximately 400 hospitals in Canada suggests that this human resource consumption becomes a $\$ 20000000$ hit for the country's health care system, affecting hospital pharmacy in particular.

As Lybecker and Esmail have described, "there are risks to drug bulk-purchasing agreements." ${ }^{5}$ While provincial governments' desire to reduce drug costs is understandable, the question remains, at what cost? Lybecker and Esmail went on to say, "there's no free lunch: implementation of bulk-purchasing agreements and their interaction with other cost containment initiatives ... may negatively impact patients, and ultimately prevent the initiative from reducing overall expenditures." ${ }^{\prime}$ They also noted that the New Zealand experience with similar cost controls "resulted in poorer care for some patients including increased prevalence of uncontrolled blood pressure, deteriorated lipid control, and worsened cardiovascular health" and that "bulk purchasing agreements may also result in monopolies or a limited number of drug suppliers."

Hospital pharmacy has made dramatic progress over the past decade in terms of optimizing medication-use policies and working with patients to manage their drug therapy. Those advances are being threatened by the need to allocate substantial resources to deal with drug shortages. At the same time, pharmacy's role in managing the drug supply chain has largely been turned over to corporate GPOs that often have limited understanding or appreciation of the shortfalls in the supply contracts that they negotiate "on our behalf". It is time for pharmacy to reclaim some of the roles it once played in managing the drug supply chain, to fulfill the fundamental responsibility of ensuring that patients receive optimal drug therapy.

References

1. Drug packaging and labelling: guidelines for manufacturers. Ottawa $(\mathrm{ON})$ : Canadian Society of Hospital Pharmacists; 2001.

2. Sellinger D. Drug shortages: the survey says... Can J Hosp Pharm. 2013;66(2):148.

3. Niccolai C, Skledar S. Updating smart pump libraries during shortages. Pharm Purch Prod. 2012;9(4):8. Available from: www.pppmag.com/ article/1094/April_2012/Updating_Smart_Pump_Libraries_during_ Shortages/

4. Vaillancourt R. Drug shortages: what can hospital pharmacists do? [editorial]. Can J Hosp Pharm. 2012;65(3):175-6.

5. Lybecker KM, Esmail N. There are risks to drug bulk-purchasing agreements. Guelph Mercury 2013 May 31 [cited 2013 Oct 23]. Available from: www. guelphmercury.com/opinion-story/3249570-there-are-risks-to-drug-bulkpurchasing-agreements/

James L Mann, MScPhm, FCSHP, spent his entire career in hospital pharmacy, most notably as Director of Pharmacy in several institutions. He was an active member of various pharmacy associations and has worked as a hospital pharmacy operational review consultant in more than 40 Canadian hospitals. He taught undergraduates on a part-time basis throughout that time and is now a retired faculty member of the Leslie Dan Faculty of Pharmacy, University of Toronto, Toronto, Ontario. He received the Distinguished Service Award of the Canadian Society of Hospital Pharmacists in 1995.

Competing interests: None declared.

Address correspondence to:

James L Mann

e-mail: 7t2442@gmail.com

This is one of a series of guest editorials, coordinated by William McLean, PharmD, FASHP, FCCP, FCSHP, and the Editorial Board of the CJHP, in which a prior recipient of the CSHP Distinguished Service Award is invited to comment on a current issue facing the profession. The guest editorialist is asked to provide a brief perspective on the evolution of that particular issue during the span of his or her career and to comment on how he or she sees that issue evolving in the years ahead. As such, these editorials combine history, reflection, and prospects for the future. 